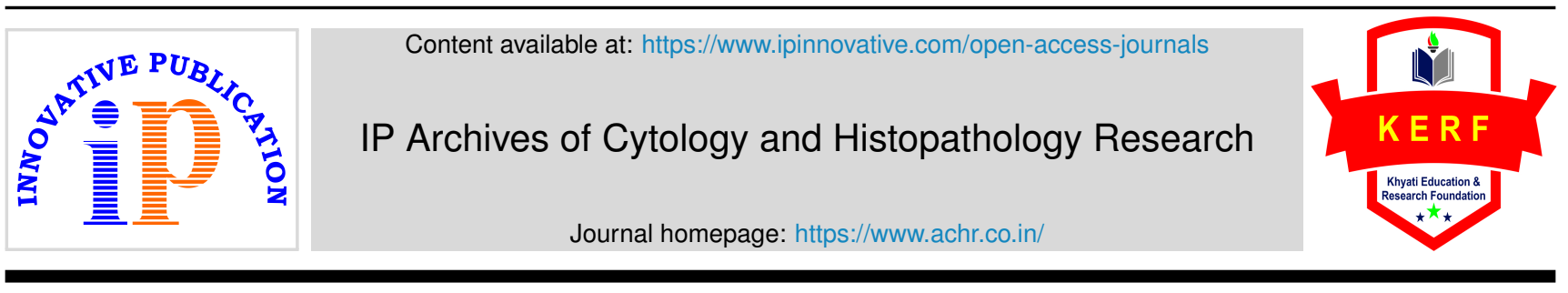

Original Research Article

\title{
Significance of detailed and careful morphological evaluation of organs in sepsis related deaths
}

\author{
Madhu Chaturvedi ${ }^{1, *}$, Aditi Parihar ${ }^{1}$ \\ ${ }^{1}$ Dept. of Pathology, LTM Medical College and General Hospital, Mumbai, Maharashtra, India
}

\section{A R T I C L E I N F O}

\section{Article history:}

Received 23-04-2021

Accepted 29-04-2021

Available online 29-05-2021

\section{Keywords:}

Sepsis

Histopathology

Autopsy

death

\begin{abstract}
A B S T R A C T
Background: In this retrospective study we studied macroscopic changes and histology of various organs in sepsis related deaths in correlation with relevant clinical, laboratory and microbiology data.

Materials and Methods: Medical records and autopsy records of all patients were reviewed where final cause of death after complete macroscopic and histological examination of organs following autopsy was given as sepsis/septic shock. Sepsis related death in diabetics, hypertensives, and pregnancy related death and unnatural deaths were excluded from this study.

Results: Sixty five cases were selected for this study involving detailed morphological examination of different organs. Most common system involved was respiratory system $(33.84 \%)$. Lungs were chief primary site of infection mainly pneumonia $(35.4 \%)$ and tuberculosis $(7.7 \%$ cases) followed by liver abscess (18\%), renal abscess/ pyelonephritis (16.4\%) and, peritonitis (16.4\%). Most frequent non- specific organ changes presented grossly as diffluent/soft mushy spleen with red pulp congestion (83.08\%) followed by mild to moderate cerebral oedema $(41.5 \%)$ and pulmonary oedema(35. $4 \%)$. Most frequent findings that contributed to death was intrapulmonary haemorrhage $(33.8 \%)$, acute tubular necrosis $(11,17 \%)$, disseminated intravascular coagulation/ micro thrombi $(8,12.3 \%)$ and, acute respiratory distress syndrome $(3,4.61 \%)$. In this study population, the commonest organism obtained on culture was Pseudomonas (24.07\%) followed by E. coli and Klebsiella (20.37\% each).

Conclusion: Careful and detailed morphological evaluation of various organs at autopsy is significant for both pathologist and clinicians to understand the course of events occurred and to reach an accurate diagnosis of sepsis related death.

(C) This is an open access article distributed under the terms of the Creative Commons Attribution License (https://creativecommons.org/licenses/by/4.0/) which permits unrestricted use, distribution, and reproduction in any medium, provided the original author and source are credited.
\end{abstract}

\section{Introduction}

Sepsis is a life-threatening entity caused by a dysregulated host response to infection. ${ }^{1}$ In many sepsis-related deaths the clinical information is scarcely available at autopsy, mostly due to the short duration of hospital's stay. Autopsy pathologist, not infrequently, has to verify and uncover an uncontrolled focus of sepsis and to search for the underlying disease process that had contributed to the death. This observational study was conducted to record the frequent morphological changes in various organs in sepsis-related deaths that assist in post-mortem tissue diagnosis of sepsis.

\footnotetext{
* Corresponding author.

E-mail address: madhu_chaturvedi@yahoo.co.in (M. Chaturvedi).
}

\section{Materials and Methods}

A retrospective study was carried out over 4 years 6 months, evaluating of medical and autopsy records at a tertiary care hospital.

All the cases included in study, had the final cause of death reported as sepsis/septic shock, after a thorough macroscopic and histological examination provided by an autopsy. Sepsis-related death in patients with diabetes mellitus, hypertension, and pregnancy and those whose death was considered unnatural were excluded from this study.

Medical and autopsy records were reviewed for (i)age, (ii)gender, (iii)duration of hospital's stay, (iv) 
vital parameters ${ }^{1}$ including blood pressure $(<90 \mathrm{mmHg}$ systolic or $<60 \mathrm{~mm} \mathrm{Hg}$ diastolic),pulse (> 90/min.), temperature $\left(>38^{\circ} \mathrm{C}\right.$ or $\left.<36^{\circ} \mathrm{C}\right)$, Altered mental status, respiratory rate ( $>30$ breaths/minute). The laboratory indicators for sepsis studied were ${ }^{2,3}$ (i) White blood cell count $(>12,000 / \mathrm{cu} \mathrm{mm},<4,000 / \mathrm{cu} \mathrm{mm}$, or $>10 \%$ immature (band) forms), (ii) Hyperglycemia (plasma glucose $>110$ $\mathrm{mg} / \mathrm{dL}$ or $7.7 \mathrm{mmol} / \mathrm{L}$ ) in the absence of diabetes, (iii) Thrombocytopenia (platelet count $<100,000 / \mu \mathrm{L}$ ), (iv) Hyperbilirubinemia (plasma total bilirubin $>4 \mathrm{mg} / \mathrm{dL}$ or $70 \mathrm{mmol} / \mathrm{L}$ ), (v) Creatinine increase $\geq 0.5 \mathrm{mg} / \mathrm{dL}$, (vi) Hyperlactatemia ( $>3 \mathrm{mmol} / \mathrm{L}$ ), and (vii) C-reactive protein(C-RP).

Supporting microbiology data showing positive cultures from various samples like blood, sputum, urine, ascitic fluid, pleural fluid, pus, skin scrapings were also documented.

The clinical impression, as given by the treating clinicians was recorded in all cases.

Thorough macroscopic examination of organs, including the brain, lungs, liver, heart, spleen, kidney, intestine, and pancreas was done to identify grossly visible septic foci. After fixation in $10 \%$ neutral buffered formalin for 2448 hours, the slides were stained with Hematoxylin \& Eosin and special stains like PAS, GMS, and Gram stain (to look for fungus and bacteria). Slides were studied for histopathological features of sepsis as documented in the literature. ${ }^{4-9}$

All the relevant ante-mortem details and post-mortem findings of each organ system were documented.

\subsection{Statistical analysis}

Statistical analysis was performed using IBM Statistical Package for the Social Sciences version 20 (SPSS v20, IBM). Categorical variables between the two groups were compared using the Chi-square test and Fisher's exact test. A p-value of $<0.05$ was considered significant.

\section{Observations and Results}

During the study period, 1657 autopsies were performed, out of which 109 were sepsis-related deaths. Sixty-five cases (49 males, 16 females) were selected for this study after excluding cases of diabetes (22), hypertension (19), and maternal mortality (13). Most of the cases were hospitalized in a general ward. The maximum and minimum duration of hospital stay was 17 days and $\leq 24$ hrs $(30.8 \%)$, respectively. The most common age group was between 41-60 years amongst males (25 cases) and 61-80 years amongst females (6 cases).

Most of the cases presented with fever (56.92\%), followed by hypotension $(40 \%)$. Few cases presented with tachypnea (29.23\%), tachycardia (23.08\%), and altered sensorium $(6.15 \%)$. Deranged laboratory parameters noted were leukocytosis $(73.85 \%)$, high C-RP value (56.92\%), high creatinine value (49.23\%), and hyperbilirubinemia $(35.38 \%)$. Few cases revealed hyperlactatemia $(29.23 \%)$, thrombocytopenia $(18.46 \%)$, leucopenia $(13.85 \%)$, and hyperglycemia $(7.69 \%)$. Table 1 shows the distribution of cases according to the system involved. Approximately $82 \%$ of the mortality in sepsis was due to isolated system involvement, with the respiratory system being the most common $(35.38 \%)$.

\subsection{Morphology of organs in sepsis related deaths}

In Tables 2, 3 and 4 are presented post-mortem findings of different organs, including the heart, lungs, kidney, brain, spleen, liver, and intestine. The internal organs showed both the site of sepsis and non-specific tissue alterations supposed to be sepsis-induced.

\subsection{Site of infection}

A site of infection was noted in all the cases. The lungs were the chief primary site of infection, mainly pneumonia $(35.4 \%)$, and tuberculosis ( $7.7 \%$ cases), followed by the liver abscess (18\%), renal abscess/ pyelonephritis (16.4\%) and, peritonitis (16.4\%). Besides the gluteal abscess, chest wall abscess, parotid abscess, epididymal-orchitis, axillary abscess, pancreatitis, cholangitis, meningitis, splenic abscess, splenic tuberculosis, intestine gangrene and fournier's gangrene were noted as other sites of infection.

\subsection{Nonspecific post mortem findings (Table 5)}

Red pulp congestion in the spleen $(83.08 \%)$, was the most frequent non- specific organ changes presented grossly as diffluent/soft mushy spleen, (Figure 1 ) followed by mild to moderate cerebral edema $(41.5 \%)$, and pulmonary edema (35. 4\%). A few other important findings were hepatic portal space inflammation (Figure 2), focal hepatic necrosis (Figure 3), and hepatic intrasinusoidal/ intravenous leukostasis $(29.2 \% ; 21.5 \% ; 21.5 \%$, respectively). However, the p-value was not significant (0.06).

Table 1: Distribution of cases according to the underlying system involved

\begin{tabular}{lcc}
\hline System & $\begin{array}{c}\text { No. of } \\
\text { cases }(\mathbf{n}=)\end{array}$ & $\begin{array}{c}\text { Percentage } \\
(\mathbf{1 0 0 \%})\end{array}$ \\
Respiratory system (RS) & 23 & 35.38 \\
Hepatobiliary system (HB) & 10 & 15.38 \\
Renal system (renal) & 8 & 12.31 \\
Gastrointestinal system (GI) & 7 & 10.76 \\
Others ( skin, soft tissue & 6 & 9.23 \\
glands) & 12 & 18.46 \\
Multiple organ failure & & \\
Total & 65 & 100 \\
\hline
\end{tabular}


Table 2: Post-mortem findings of heart $[n=2]$ and lungs $[n=29]$

\begin{tabular}{ll}
\hline Heart (n=2) & Lungs (n-29) \\
Histopathology n= & Histopathology n= \\
Interstitial edema (1) & Pneumonia (23) \\
Interstitial Hemorrhages(1) & Lung abscess (3) \\
Myocarditis (1) & Pulmonary TB (5) \\
Endocarditis (1) & Pulmonary edema(23) \\
Interstitial mononuclear cells & Intrapulmonary hemorrhage \\
$(2)$ & $(22)$ \\
Septic emboli (2) & Microthrombi (7) \\
& Intravenous leucostasis (6) \\
& Interstitial pneumonitis(1) \\
\hline
\end{tabular}

Table 3: Post-mortem findings of liver [ $n=15]$ and kidney [ $n=13]$

\begin{tabular}{ll}
\hline Liver $(\mathbf{n}=\mathbf{1 5})$ & Kidney $(\mathbf{n = 1 3})$ \\
Histopathology(n=) & $\begin{array}{l}\text { Histopathology }(\mathrm{n}=) \\
\text { Acute tubular necrosis } \\
\text { Focal necrosis(14) }\end{array}$ \\
$\begin{array}{l}\text { (ATN)(10) } \\
\text { Ductular inflammation (6) }\end{array}$ & $\begin{array}{l}\text { Renal abscess (5) } \\
\text { Ductular proliferation (7) }\end{array}$ \\
Cholestasis (6) & Bacterial colonies (1) \\
Intrasinusoidal & \\
leucostasis/fibrin(14) & \\
Kupffer cell hyperplasia (1) & \\
Portal tract inflammation (13) & \\
Bacterial colonies (2) & \\
TB lesion (2) & \\
\hline
\end{tabular}

Table 4: Post-mortem findings of brain [n=28], spleen [ $n=16]$, intestine $[\mathrm{n}=23]$

\begin{tabular}{lll}
\hline $\begin{array}{l}\text { Brain (n=28) } \\
\text { Histopathology } \\
(\mathrm{n}=)\end{array}$ & $\begin{array}{l}\text { Spleen }(\mathbf{1 6}) \\
\text { Histopathology } \\
(\mathrm{n}=)\end{array}$ & $\begin{array}{l}\text { Intestine }(\mathbf{n = 2 3}) \\
\text { Histopathology } \\
(\mathrm{n}=)\end{array}$ \\
Meningitis (1) & Splenitis (6) & $\begin{array}{l}\text { Serosal } \\
\text { Exudates(18) }\end{array}$ \\
$\begin{array}{l}\text { Cerebral edema } \\
(27)\end{array}$ & $\begin{array}{l}\text { White pulp } \\
\text { atrophy(11) } \\
\text { TB spleen(2) }\end{array}$ & $\begin{array}{l}\text { Ulcer (9) } \\
\text { TB intestine (3) } \\
\text { Gangrene (3) } \\
\end{array}$ \\
& & Microthrombi (1) \\
\hline
\end{tabular}

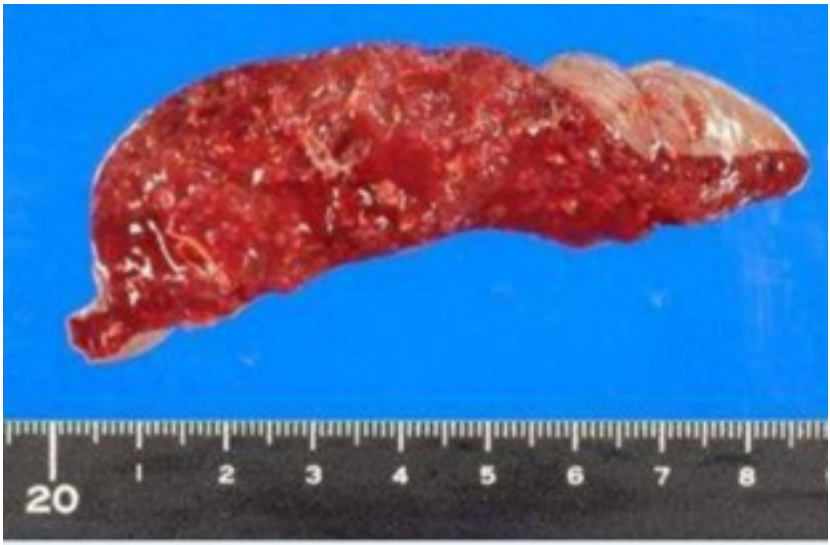

Fig. 1: Shows soft 'mushy' spleen characteristically seen in sepsis.
Table 5: Non-specific post-mortem findings in the study group $[\mathrm{n}=65$ ]

\begin{tabular}{lcc}
\hline Non-specific findings & $\begin{array}{c}\text { No. of } \\
\text { patients }(\mathbf{6 5})\end{array}$ & $\begin{array}{c}\text { Percentage } \\
(\mathbf{1 0 0 \% )}\end{array}$ \\
Epicardial haemorrhages & 1 & 1.5 \\
Epicarditis/myocarditis & 4 & 6.2 \\
Portal inflammation liver & 19 & 29.2 \\
Splenitis & 6 & 9.2 \\
Interstitial inflammation & 12 & 18.6 \\
kidney & & \\
Focal necrosis kidney & 10 & 15.4 \\
Focal necrosis liver & 14 & 21.5 \\
Cerebral edema & 27 & 41.5 \\
Pulmonary edema & 23 & 35.4 \\
Interstitial edema heart & 1 & 1.5 \\
Swollen kidney & 10 & 15.4 \\
Intravenous leucostasis lung & 6 & 9.2 \\
Intrasinusoidal leucostasis & 14 & 21.5 \\
liver & & \\
Red pulp congestion spleen & 54 & 83 \\
White pulp atrophy spleen & 11 & 16.9 \\
Bacterial colony liver & 2 & 3.1 \\
Bacterial colony kidney & 1 & 1.5 \\
\hline p value =.06(insignificant). & &
\end{tabular}

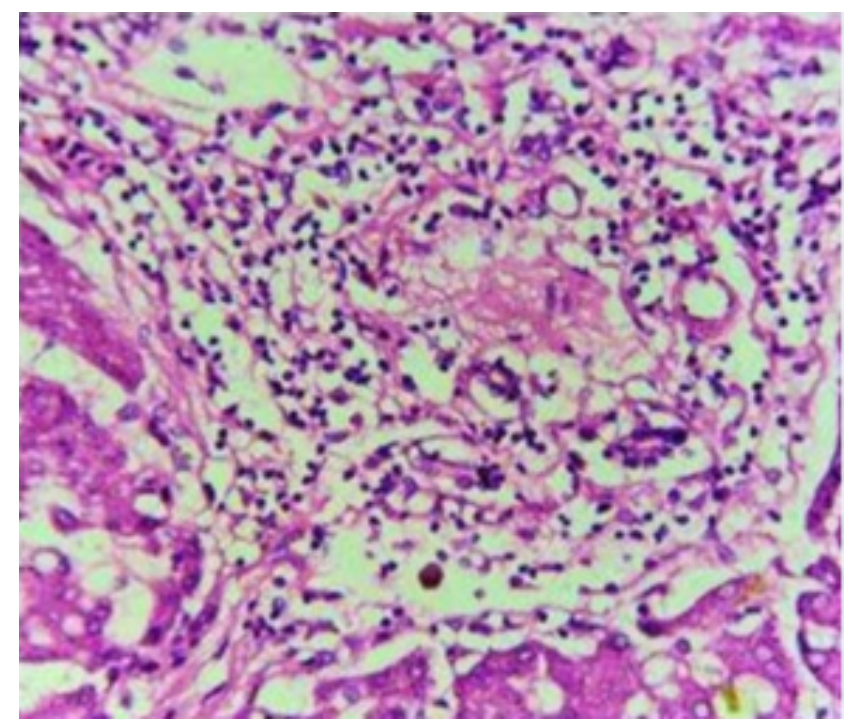

Fig. 2: (H\&E, 100X) Shows portal tract inflammation liver

\subsection{Significant post-mortem findings and complications that can cause death}

The most frequent findings that contributed to death was intrapulmonary hemorrhage $(33.8 \%)$, (Figure 4), acute tubular necrosis $(17 \%)$, disseminated intravascular coagulation/ microthrombi $(12.3 \%)$ and, acute respiratory distress syndrome (4.61\%). However, p-value was not significant $>0.5$. 


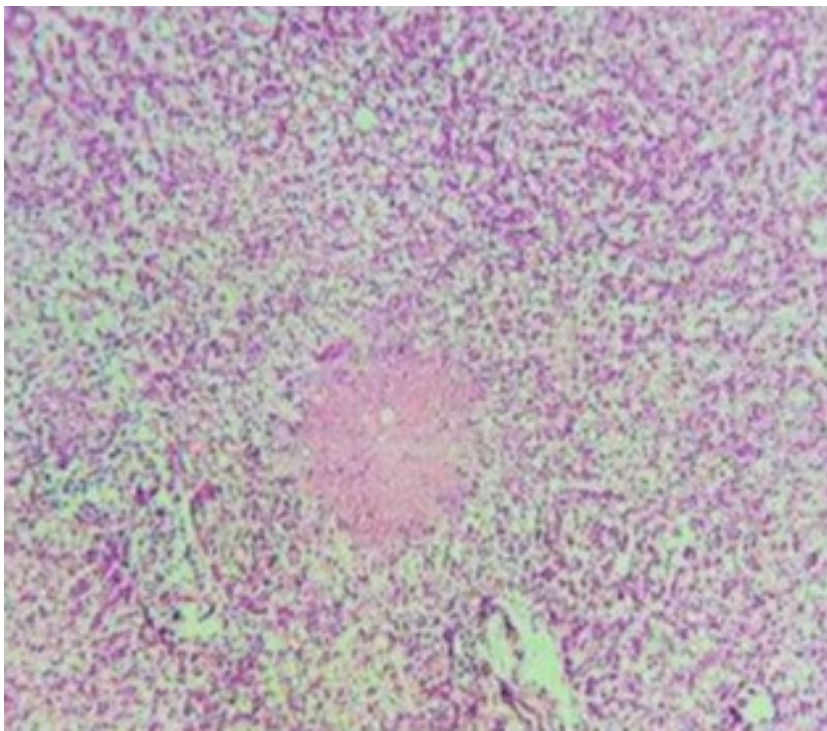

Fig. 3: (H\&E, 100X) Shows centriacinar necrosis liver

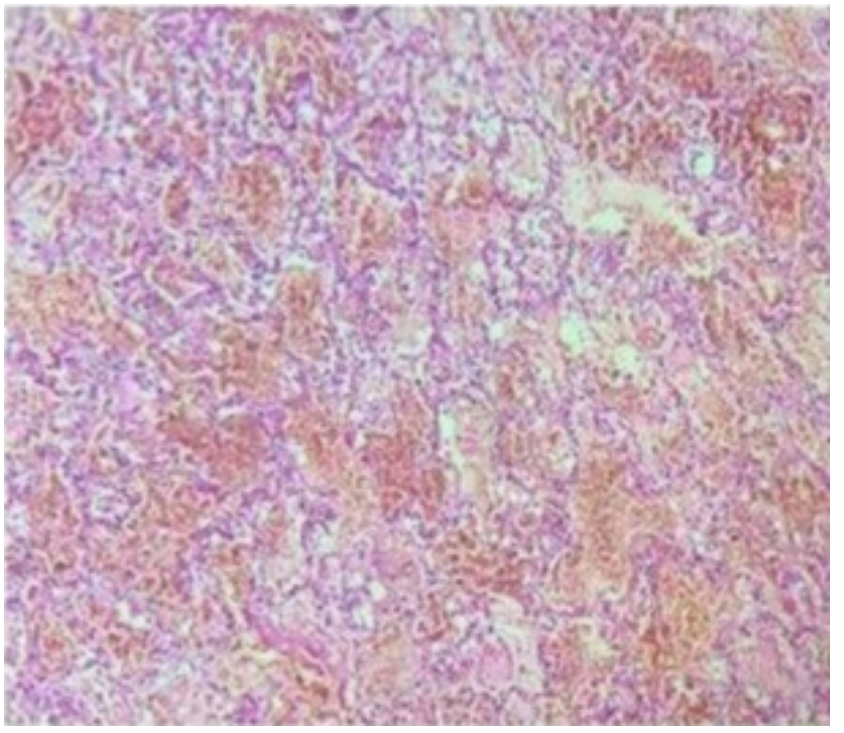

Fig. 4: (H\&E, 100X) Shows marked haemorrhage in the alveoli (Intrapulmonary Haemorrhage)

\subsection{Significant co-morbidities and conditions that can contribute to death}

Fifteen (24.62\%) cases had co-morbidities including chronic liver disease (15.38\%), chronic kidney disease $(3.08 \%)$, chronic heart disease $(3.08 \%)$ and, chronic pulmonary disease $(1.54 \%)$.

\subsection{Microbiological culture in the study group}

To confirm the clinical and radiological diagnosis, multiple ante mortem samples were sent for microbiology. A total of 96 samples, taken from different sites, were studied for microbiological studies. These included 11 respiratory samples of sputum or endotracheal secretions, 36 blood samples, 14urine samples, 24 samples of peritoneal fluid, 11 samples of pus or wound swab or tissue. 54 samples $(56.25 \%)$ showed positive growth. The, most significant number of positive cultures was for the urine samples (78.57\%) followed by respiratory samples, including sputum and endotracheal secretions $(72.73 \%)$. Significant p-value $<.05$ was observed in urine samples. In this study population, the commonest organism obtained on culture was Pseudomonas spp (24.07\%) followed by Escherichia coli. and Klebsiella spp (20.37\% each). .

\section{Discussion}

In this study, sepsis-related death was seen more frequently in males (75.38\%) in the age group of 41-60 years (43.08\%) compared to females $(24.61 \%)$ in the age group of 61-80 years. ${ }^{10,11}$ The basis for these disparities has been postulated to relate to hormonal differences between genders. Estrogen levels and plasma cytokine imbalance may contribute to the differences in the inflammatory response and the development of sepsis. ${ }^{11-13}$

Elderly ( $>60 \mathrm{yrs}$ ) age group have been reported to be most common age group affected by sepsis. In the current study, age group affected commonly was 41-60 years. Eleven out of 28 patients $(39.3 \%)$ in the age group 41-60 years had co-morbidity like chronic liver disease or chronic kidney disease or heart disease. This differential distribution in the age groups can be attributed to the chronic co-morbid medical conditions that affect the immune system (diabetes, chronic renal failure, and HIV). ${ }^{14}$

In this study most common site of infection was lung and most frequent contributor for sepsis - related death was intrapulmonary hemorrhage. Intrapulmonary hemorrhage is a life threatening complication and needs a prompt treatment. Its pathophysiology is alveolar microcirculation injury. ${ }^{15-17}$

Red pulp congestion of spleen, cerebral edema and pulmonary edema were frequently observed non specific findings that supported the autopsy diagnosis of sepsisrelated death. ${ }^{18-21}$ Sepsis causes imbalance between proinflammatory and antiinflammatory repsonse and microbials and their products are recognised by immune cells initiating production of cytokines and a cascade of events leading to organ damage. ${ }^{22}$

\section{Conclusion}

This study highlights that a detailed and careful evaluation of the morphology of various organs at autopsy plays an important role in reaching a diagnosis of sepsis-related death and to understand the pathophysiology of sepsis better. 


\section{Source of Funding}

No financial support was received for the work within this manuscript.

\section{Conflict of Interest}

The authors declare they have no conflict of interest.

\section{References}

1. Opal SM, Rubenfeld GD, Der P, Vincent J, Angus DC. The Third International Consensus Definitions for Sepsis and Septic Shock (Sepsis-3). JAMA. 2016;315(8):801-10.

2. Levy MM, Fink MP, Marshall JC, E A, Angus D, Cook D, et al. SCCM/ESICM/ACCP/ATS/SIS International Sepsis Definitions Conference. Crit Care Med. 2001;31(4):1250-6.

3. Dellinger RP, Levy MM, Rhodes A, Bs MB, Annane D, Gerlach $\mathrm{H}$, et al. Surviving Sepsis Campaign : International Guidelines for Management of Severe Sepsis and Septic Shock. Crit Care Med. 2013;41(2):580-637.

4. Sato T, Kamiyama Y, Jones R, Cowley R, Trump B. Ultrastructural study on kidney cell injury following variious types of shock in 26 immediate autopsy patients. Adv Shock Res. 1978;1:55-69.

5. Schmittinger CA, Dünser MW, Torgersen C, Luckner G, Lorenz I, Schmid S, et al. Histologic pathologies of the myocardium in septic shock: A prospective observational study. Shock. 2013;39(4):329-35.

6. Feig JA, Cina SJ. Evaluation of Characteristics Associated With Acute Splenitis ( Septic Spleen ) as Markers of Systemic Infection. Arch Pathol Lab Med. 2001;125:888-91.

7. Mukherjee T, Mukherjee S, Singh N, Singh A. iMedPub Journals Retrospective Analysis of Histopathological and Microbiological Correlation of Autopsy Series Keywords. J Clin Med Ther. 2017;2(2):1-4.

8. Torgersen C, Moser P, Luckner G, Mayr V, Jochberger S, Hasibeder WR, et al. Macroscopic postmortem findings in 235 surgical intensive care patients with sepsis. Anesth Analg. 2009;108(6):1841-7.

9. Tsokos M. Pathology of Sepsis. Essentials Autops Pract. 2006;p. 39-85. d01:10.100//1-84628-026-5 3

10. Rudd EK, Sarah CJ, Kareha MA. Global, regional, and national sepsis incidence and mortality,1990-2017: analysis for the Global Burden of Disease Study. Lancet. 2020;395:200-11.

11. Angus DC, Linde-Zwirble WT, Lidicker J, Clermont G, Carcillo J, Pinsky MR, et al. Epidemiology of severe sepsis in the United States: Analysis of incidence, outcome, and associated costs of care. Crit Care Med. 2001;29(7):1303-10.
12. Asai K, Hiki N, Mimura Y. Gender differences in cytokine secretion by human peripheral blood mononuclear cells: Role of estrogen in modulating LPS-induced cytokine scretion in an ex vivo septic model. Shock. 2001;16:340-3.

13. Esper AM, Moss M, Lewis CA, Nisbet R, Mannino DM, Martin GS, et al. The role of infection and comorbidity: Factors that influence disparities in sepsis. Crit Care Med. 2006;34(10):2576-82.

14. Dombrovskiy VY, Martin AA, Sunderram J, Paz HL. Rapid increase in hospitalization and mortality rates for severe sepsis in the United States: A trend analysis from 1993 to 2003. Crit Care Med. 2007;35(5):1244-50

15. Torgersen C, Moser P, Luckner G, Mayr V, Jochberger S, Hasibeder WR, et al. Macroscopic postmortem findings in 235 surgical intensive care patients with sepsis. Anesth Analg. 2009;108(6):1841-7.

16. Mukherjee T, Mukherjee S, Singh N, Singh A. Retrospective Analysis of Histopathological and Microbiological Correlation of Autopsy Series. J Clin Med Ther. 2017;2(2):1-4.

17. Ranke FMV, Zanetti G, Hochhegger B. Infectious Diseases Causing Diffuse Alveolar Hemorrhage in Immunocompetent Patients: A Stateof-the-Art Review. Lung. 2013;191:9-18.

18. Garofalo. Histopathological changes of organdysfunction in sepsis. Intensive Care Med Exp. 2019;7(1):1-15.

19. Koskinas J, Gomatos IP, Tiniakos DG, Memos N, Boutsikou M, Garatzioti A. Liver histology in ICU patients dying from sepsis : A clinico-pathological study. World J Gastroenterol. 2008;14(9):138993.

20. Der P, Opal SM. Host - pathogen interactions in sepsis. Lancet Infect Dis. 2008;8:32-43.

21. Ramos-Casals M, Brito-Zerón P, López-Guillermo A, Khamashta MA, Bosch X. Adult haemophagocytic syndrome. Lancet. 2013;6736(13):1-14.

22. Kumar V, Abbas AK, Aster JC. Hemodynamic Disorders, Thomboembolic Disease and Shock. In: Robbins and Cotran Pathologic Basis of Disease. 9th Edn. Philadelphia: Elsevier Saunders; 2015 .

\section{Author biography}

Madhu Chaturvedi, Additional Professor

Aditi Parihar, Ex. Resident

Cite this article: Chaturvedi M, Parihar A. Significance of detailed and careful morphological evaluation of organs in sepsis related deaths. IP Arch Cytol Histopathology Res 2021;6(2):76-80. 